\title{
Postinfection Activity of Synthetic Antimicrobial Peptides Against Stemphylium vesicarium in Pear
}

\author{
M. Puig, C. Moragrega, L. Ruz, E. Montesinos, and I. Llorente
}

Institute of Food and Agricultural Technology-XaRTA-CIDSAV, University of Girona, Spain. Accepted for publication 7 May 2014.

\begin{abstract}
Puig, M., Moragrega, C., Ruz, L., Montesinos, E., and Llorente, I. 2014. Postinfection activity of synthetic antimicrobial peptides against Stemphylium vesicarium in pear. Phytopathology 104:1192-1200.

Brown spot of pear is a fungal disease of economic importance caused by Stemphylium vesicarium that affects the pear crops in Europe. Due to the characteristics of this disease and the moderate efficacy of available fungicides, the effectiveness of control measures is very limited; however, synthetic antimicrobial peptides (AMPs) may be a complement to these fungicides. In the present study, 12 AMPs of the CECMEL11 library

were screened for fungicidal activity against $S$. vesicarium. In vitro experiments showed that eight AMPs significantly reduced the germination of conidia. The most effective peptides, BP15, BP22, and BP25, reduced fungal growth and sporulation at concentrations below $50 \mu \mathrm{M}$. Leaf assays showed that preventive application of BP15 and BP22 did not reduce infection; however, when the peptides were applied curatively, infection was significantly reduced. The use of a BP15 fluorescein 5 -isothiocyanate conjugate revealed that the peptide binds to hyphae and germ tubes and produces malformations that irreversibly stop their development.
\end{abstract}

Brown spot of pear (Pyrus communis L.) is a disease caused by the fungus Stemphylium vesicarium (Wallr.) E. G. Simmons, which has been reported in the pear-growing areas of Spain, Italy, France, The Netherlands, Belgium, and Portugal (18). The symptoms include necrotic spots on fruit, leaves, and shoots. Despite the application of control measures, the disease may reduce yield by 1 to $10 \%$ (20). Brown spot of pear is chemically controlled with preventative fungicide sprays containing dithiocarbamates (thiram and mancozeb), strobilurins (kresoxim-methyl and trifloxystrobin), or captan (18). Disease control is limited by the moderate efficacy of available fungicides when the disease pressure is high. The emergence of isolates of $S$. vesicarium that are resistant to strobilurins decreases the efficacy of disease control $(2,3)$. Thus, there is a need for new products to control brown spot of pear, and antimicrobial peptides (AMPs) may represent an alternative or complement to the existing fungicides.

AMPs are produced by a wide range of organisms, including bacteria, fungi, insects, plants, and animals $(12,23)$. In recent years, AMPs have been studied as an alternative to control viruses, bacteria, and fungi that infect plants, animals, and humans $(15-17,24,31)$. In general, AMPs have a net positive charge and the ability to assume an amphipathic structure, features involved in binding and disruption of prokaryote and eukaryote cell membranes (25). Some AMPs have the capacity to control phytopathogenic fungi, such as Botrytis cinerea, Alternaria alternata, Penicillium digitatum, P. expansum, P. italicum, Fusarium oxysporum, and Aspergillus niger, as well as bacteria, including Erwinia amylovora, Pseudomonas syringae, and Xanthomonas vesicatoria $(1,4,5,21,22,26,28)$. A library of synthetic linear undecapeptides, cecropin A(1-7)-melittin hybrids (CECMEL11), has been reported with activity against plant-pathogenic bacteria and fungi (5). The minimal inhibitory concentrations (MICs) for some of these compounds is in the range of the MICs for common anti-

Corresponding author: I. Llorente; E-mail address: isidre.llorente@udg.edu

http://dx.doi.org/10.1094/PHYTO-02-14-0036-R

(c) 2014 The American Phytopathological Society biotics $(5,6)$. Some members of the CECMEL11 library showed minimal cytotoxicity and phytotoxicity as well as low susceptibility to protease degradation; thus, they are good candidates that can be further tested in new pathosystems $(5,6)$.

The objectives of the present work were to evaluate and select AMPs with a capacity to control brown spot of pear and to determine the best strategy for application of these compounds in relation to pathogen inoculation. A set of 12 peptides from the CECMEL11 library were screened in vitro to determine inhibition of growth and sporulation of $S$. vesicarium. The most effective peptides were evaluated in detached leaf assays using preventative and curative strategies of application, and the interaction of peptides and fungal structures was analyzed using fluorescence microscopy.

\section{MATERIALS AND METHODS}

Peptide synthesis. The compounds used were a selection of undecapeptides from the CECMEL11 library (Table 1). The peptides were purchased at $>90 \%$ purity from LIPPSO (University of Girona, Girona, Spain) or the CASLO Laboratory (CASLO ApS, Lyngby, Denmark). All peptides were synthesized using solidphase methodology with 9-fluorenylmethoxycarbonyl (Fmoc)type chemistry, tert-butyloxycarbonyl side-chain protection for Lys and Trp, and tert-butyl for Tyr, as previously described $(5,13)$. BP15 was conjugated with fluorescein 5-isothiocyanate (FITC) at the N-terminal end via an N-terminal Ahx linker and was amidated at the C-terminus (CASLO ApS).

Fungal strains and growth media. $S$. vesicarium strains EPS26 and EPS21, isolated from infections in P. communis fruit, obtained from the Culture Collection of the Institute of Food and Agricultural Technology (Girona, Spain) were used. The strains were cultured on tomato agar ( $800 \mathrm{ml}$ of distilled water, $10 \mathrm{~g}$ of tomato juice, $2.3 \mathrm{~g}$ of $\mathrm{CaCO}_{3}$, and $12.8 \mathrm{~g}$ of agar) in petri dishes for 7 to 10 days at $22.5^{\circ} \mathrm{C}$ with a 16 -h-light photoperiod in a growth cabinet (I-30BLL Plant Biology Chamber; Percival Scientific Inc., Perry). Conidia were collected from the agar surface, transferred to distilled water, and filtered. The concentration of 
the suspension was determined by counting the conidia in 5 drops (10 $\mu \mathrm{l}$ each) under a microscope. The conidial concentrations used in the antifungal assays were $10^{3}$ or $10^{4}$ conidia $/ \mathrm{ml}$.

Screening of antifungal peptides against $S$. vesicarium. The antifungal effect of peptides on $S$. vesicarium was determined in vitro. Twelve synthetic AMPs selected from the CECMEL11 library (Table 1) were evaluated: BP15, BP21, BP22, BP23, $\mathrm{BP} 24, \mathrm{BP} 25, \mathrm{BP} 30, \mathrm{BP} 34, \mathrm{BP} 35, \mathrm{BP} 37, \mathrm{BP} 38$, and BP75. The lyophilized peptides were solubilized in sterile Milli-Q water to obtain a concentration of $400 \mu \mathrm{M}$; subsequently, stock solutions of peptides were prepared at appropriate concentrations and stored at $-20^{\circ} \mathrm{C}$ until use. Experiments were performed using two strains of $S$. vesicarium, EPS26 and EPS21, in 48-well plates (Nunc, Roskilde, Denmark). Conidial suspensions (80 $\mu \mathrm{l}, 10^{3}$ conidia/ml) were mixed with $160 \mu$ of growth medium (containing 5\% agar), and $80 \mu \mathrm{l}$ of the corresponding peptide and concentration $(4 \times)$ was added. The final volume in each well was $320 \mu \mathrm{l}$, and $0.003 \%$ (wt/vol) of chloramphenicol was included to prevent bacterial growth. The peptide concentrations evaluated were $5,10,25,50$, and $100 \mu \mathrm{M}$. The experiment consisted of three replicates of each strain, peptide, and concentration combination. The multiwell plates were incubated at $22.5^{\circ} \mathrm{C}$ with a 16-h-light photoperiod for $48 \mathrm{~h}$. A nontreated control and a positive control using the fungicide thiram $(2 \mathrm{mg}$ a.i./ml $)$ were included. Conidial germination was monitored microscopically during incubation for 0,24 , and $48 \mathrm{~h}$ by counting the number of germinated and nongerminated conidia and measuring the germ tube lengths. A conidium was considered germinated if the length of the longest germ tube exceeded the length of the conidium. After incubation, the growth of the germ tube was stopped with a lactophenol blue solution. Measurements were performed with an optical microscope (AXIO SCOPE A1; Carl Zeiss, Gottingen, Germany) with a digital camera using the image analysis software AXIOVISION LE 4.7.1 (Carl Zeiss Microscopy GmbH, Munich). The MIC of each peptide was defined as the lowest concentration required to inhibit conidial germination.

Effect of selected peptides on the growth and sporulation of S. vesicarium. The peptides BP15, BP22, and BP25 were selected based on their ability to inhibit conidial germination. Their efficacy for the inhibition of growth and sporulation was determined. Experiments were performed with $S$. vesicarium strain EPS26 using 48 -well plates. Conidial suspensions $\left(5 \mu \mathrm{l}, 10^{3}\right.$ conidia $\left./ \mathrm{ml}\right)$ were added to $240 \mu \mathrm{l}$ of potato dextrose agar (1.33 $\times$ ) supplemented with $80 \mu \mathrm{l}$ of peptide solution $(4 \times)$. For each peptide, three concentrations were tested: 10,25 , and $50 \mu \mathrm{M}$ for BP15 and 25,50 , and $100 \mu \mathrm{M}$ for the other peptides. A nontreated control and a positive control using thiram $(2 \mathrm{mg}$ a.i./ml) were also included. The experiment consisted of three replicates per treatment. The plates were incubated at $22.5^{\circ} \mathrm{C}$ with $16 \mathrm{~h}$ of light and $8 \mathrm{~h}$ of darkness for a period of $72 \mathrm{~h}$. The growth of the mycelium in each well was evaluated visually according to the following index (I): $0=$ no growth, $1=$ beginning of growth, $2=$ mycelium covers a third of the well, $3=$ mycelium covers half of the well, $4=$ mycelium covers more than half of the well, and $5=$ mycelium completely covers the well. The percentage of growth for each repetition was calculated using the following equation:

$$
G=\left[\sum_{n=1}^{N}\left(\frac{I n}{5 \times N}\right)\right] \times 100
$$

where $\mathrm{G}$ is the percentage of growth $(\%), \mathrm{I}_{\mathrm{n}}$ is the growth index of each well, $\mathrm{N}$ is the total number of wells assessed, and 5 is the maximum level of the growth index.

Sporulation was evaluated at the end of the incubation period. Five drops $(10 \mu \mathrm{l}$ each) in each well were observed using optical compound microscopy. To prevent fungal growth during observations, lactophenol blue solution $(1 \%)$ was added to each well. The experiment was conducted twice.
Fungicidal activity against nongerminated $S$. vesicarium conidia. In this assay, the objective was to determine the sporicidal effect of the peptides BP15, BP22, and BP25. Conidial suspensions $\left(50 \mu \mathrm{l}, 10^{3}\right.$ conidia $\left./ \mathrm{ml}\right)$ were mixed with $450 \mu \mathrm{l}$ of the appropriate peptide stock solutions to reach final concentrations of 25,50 , and $100 \mu \mathrm{M}$ (for BP22 and BP25) and 10, 25, and $50 \mu \mathrm{M}$ (for BP15). In the nontreated control, conidia were incubated in distilled water. The suspensions were incubated for 6,24 , and $48 \mathrm{~h}$ at $22.5^{\circ} \mathrm{C}$. To remove the peptide after each treatment, the samples were centrifuged twice $(2 \mathrm{~min}$ at 5,000 $\mathrm{rpm})$ and the supernatant was decanted. The pellet with conidia was resuspended in $150 \mu \mathrm{l}$ of water, and three drops (20 $\mu \mathrm{l}$ each) of each treatment were spread onto tomato agar plates (three repetitions $\times$ three drops per treatment). The cultures were incubated at $22.5^{\circ} \mathrm{C}$ with $16 \mathrm{~h}$ of light and $8 \mathrm{~h}$ of darkness. At 3 and 5 days after incubation, fungal growth was measured according to the following index (I): $0=$ no growth, $1=0<$ diameter $<1 \mathrm{~cm}, 2=1 \mathrm{~cm} \leq$ diameter $<2 \mathrm{~cm}, 3=2 \mathrm{~cm} \leq$ diameter $<3 \mathrm{~cm}$, and $4=$ diameter $\geq 3 \mathrm{~cm}$. The percentage of growth for each repetition was calculated using the equation described above, with 4 as the maximum level.

Fluorescence microscopy. To study the interaction between BP15 and $S$. vesicarium, conidia were incubated in sterile water with 10 or $100 \mu \mathrm{M}$ BP15-FITC for different time periods. BP15FITC was applied to nongerminated conidia and, at 6 or $15 \mathrm{~h}$ after the start of germination, samples were removed and observed at 0 , 3,6 , and $24 \mathrm{~h}$ using an epifluorescence microscope (Axio Scope A1, Carl Zeiss, Gottingen, Germany) with filter set 38 (excitation, 470/40; emission, 525/50).

Evaluation of preventative and curative strategies for peptide application to control brown spot on pear leaves. Ex vivo assays were performed on young detached 'Conference' pear leaves obtained from potted plants cultivated in the greenhouse. Two strategies of control were evaluated: preventative and curative (before or after pathogen inoculation, respectively). For the preventative strategy, the leaf surface was disinfected by immersion in $1 \%$ sodium hypochlorite solution and rinsed twice in distilled sterile water. Then, the leaves were placed with the abaxial surface face up on moistened filter paper in plastic boxes and were treated with the peptides BP15 and BP22 at 50, 100, and $200 \mu \mathrm{M}$ using an airbrush. Thereafter, the leaves were left at room temperature for $3 \mathrm{~h}$, and four $30-\mu \mathrm{l}$ drops of a suspension of $S$. vesicarium EPS26 $\left(10^{3}\right.$ conidia/ml $)$ were deposited on the leaf surface.

For the curative treatment, four 30- $\mu$ l drops of $S$. vesicarium EPS26 $\left(10^{3}\right.$ conidia/ml $)$ were deposited on the leaf surface and, after $15 \mathrm{~h}$ of incubation, the leaves were treated with peptides as

TABLE 1. Minimal inhibitory concentration (MIC) of peptides for complete inhibition of conidial germination of two strains of Stemphylium vesicarium (EPS26 and EPS21) in vitro

\begin{tabular}{|c|c|c|c|}
\hline \multirow[b]{2}{*}{ Peptide } & \multirow[b]{2}{*}{ Sequence } & \multicolumn{2}{|c|}{$\operatorname{MIC}(\mu \mathrm{M})^{\mathrm{y}}$} \\
\hline & & EPS26 & EPS21 \\
\hline BP15 & Ac-KKLFKKILKVL-NH ${ }_{2}$ & 10 & 10 \\
\hline $\mathrm{BP} 21$ & Ac-FKLFKKILKVL-NH ${ }_{2}$ & 100 & nd \\
\hline $\mathrm{BP} 22$ & pTs-FKLFKKILKVL-NH ${ }_{2}$ & 50 & nd \\
\hline $\mathrm{BP} 23$ & Bz-FKLFKKILKVL-NH ${ }_{2}$ & 100 & nd \\
\hline BP24 & Bn-FKLFKKILKVL- $\mathrm{NH}_{2}$ & 100 & 100 \\
\hline BP25 & Ac-YKLFKKILKVL- $\mathrm{NH}_{2}$ & 50 & 100 \\
\hline BP30 & pTs-KKLFKKILKVL- $\mathrm{NH}_{2}$ & $>100^{z}$ & $>100^{z}$ \\
\hline BP34 & Ac-LKLFKKILKVL-NH ${ }_{2}$ & $>100^{z}$ & nd \\
\hline BP35 & pTs-LKLFKKILKVL- $\mathrm{NH}_{2}$ & 100 & nd \\
\hline BP37 & Bn-LKLFKKILKVL- $\mathrm{NH}_{2}$ & $>100^{z}$ & 100 \\
\hline BP38 & Ac-WKLFKKILKWL-NH & 100 & 100 \\
\hline BP75 & $\mathrm{Bn}-\mathrm{YKLFKKILKFL-} \mathrm{NH}_{2}$ & $>100^{z}$ & $>100^{\mathrm{z}}$ \\
\hline
\end{tabular}

y Abbreviation: $\mathrm{nd}=$ not determined.

${ }^{\mathrm{z}}$ Complete inhibition of conidial germination was not observed at the highest peptide concentration $(100 \mu \mathrm{M})$. 
described above. In each assay, a nontreated control, corresponding to leaves treated with water, and a positive control, corresponding to leaves treated with thiram at the commercial dose, were included. Three replicates (with three leaves per replicate) were treated with each peptide at the various concentrations. Inoculated leaves were incubated at $22.5^{\circ} \mathrm{C}$ with a 16 -h-light photoperiod for 7 days. Disease severity was determined 3, 4, and 7 days after treatment or pathogen inoculation. Disease was assessed for each inoculation according to the following index (I): $0=$ no infection, $1=0<$ necrosis $<2.5 \mathrm{~mm}, 2=2.5 \mathrm{~mm} \leq$ necrosis $<5 \mathrm{~mm}, 3=5 \mathrm{~mm} \leq$ necrosis $<10 \mathrm{~mm}$, and $4=$ necrosis $\geq$ $10 \mathrm{~mm}$. The disease severity (\%) was calculated per leaf with the equation described above using 4 as the maximum index level. The experiment was repeated twice.

To determine the effect of a time delay between the start of germination and peptide treatment, additional experiments were performed. Detached pear leaves were inoculated with $S$. vesicarium as in the previous assays. Then, the leaves were treated with $100 \mu \mathrm{M}$ BP15 at $6,12,15,18$, and $24 \mathrm{~h}$ after inoculation to permit conidial germination and tissue infection. Controls with the reference fungicide thiram $(2 \mathrm{mg}$ a.i./ml $)$ and nontreated leaves were included for each time point. Three replicates (with three leaves per replicate) were performed per treatment. The assay was repeated twice. Disease severity was determined 3, 4, and 7 days after the inoculation, as described above.

Additionally, to visualize the interaction between BP15 and the fungal structures on the leaf surface, $100 \mu \mathrm{M}$ BP15-FITC was used. Treatments were performed 6 and $15 \mathrm{~h}$ after the onset of infection. The samples were microscopically observed at $0,3,6$, and $24 \mathrm{~h}$ after peptide application using the previously described methodology.

Morphological changes in $S$. vesicarium due to BP15 treatment. Leaves from the ex vivo assay were observed by scanning electron microscopy (SEM) 10 days after peptide application. The leaves used in these experiments were those treated with BP15 and $\mathrm{BP} 22$ at $100 \mu \mathrm{M}$, nontreated control leaves, and thiram fungicide-treated control leaves. Portions of the leaves were fixed with $2.5 \%$ (wt/vol) glutaraldehyde and paraformaldehyde $(1 \%)$ in $0.1 \mathrm{M}$ cacodylate buffer, $\mathrm{pH}$ 7.4. The samples were filtered, washed, and dehydrated successively in a graded ethanol series $(50,75,80,90,95,100,100$, and $100 \%)$, critical point dried, and sputter-coated with a $22.5-\mathrm{nm}$ gold layer at $1.5 \mathrm{KV}$ with a deposition current of $30 \mathrm{~mA}$ for 2 min using a sputter coater (K550, Emitech; Röntgenanalytik Messtechnik GmbH, Taunusstein, Germany). The analysis was carried out with a Zeiss DSM 960 scanning electron microscope (Carl Zeiss, Oberkchen, Germany). Digital images were collected and processed using ESPRIT 1.9 analytical software (Bruker Nano GmbH, Berlin, Germany).

Statistical analysis. The statistical significance of the data was analyzed using the SAS 9.2 software program (SAS Institute Inc., Cary, NC). In all experiments, the data sets were tested for equality of variances (Bartlett) and normality (Shapiro-Wilk). The effect of selected peptides on the growth and sporulation of $S$.
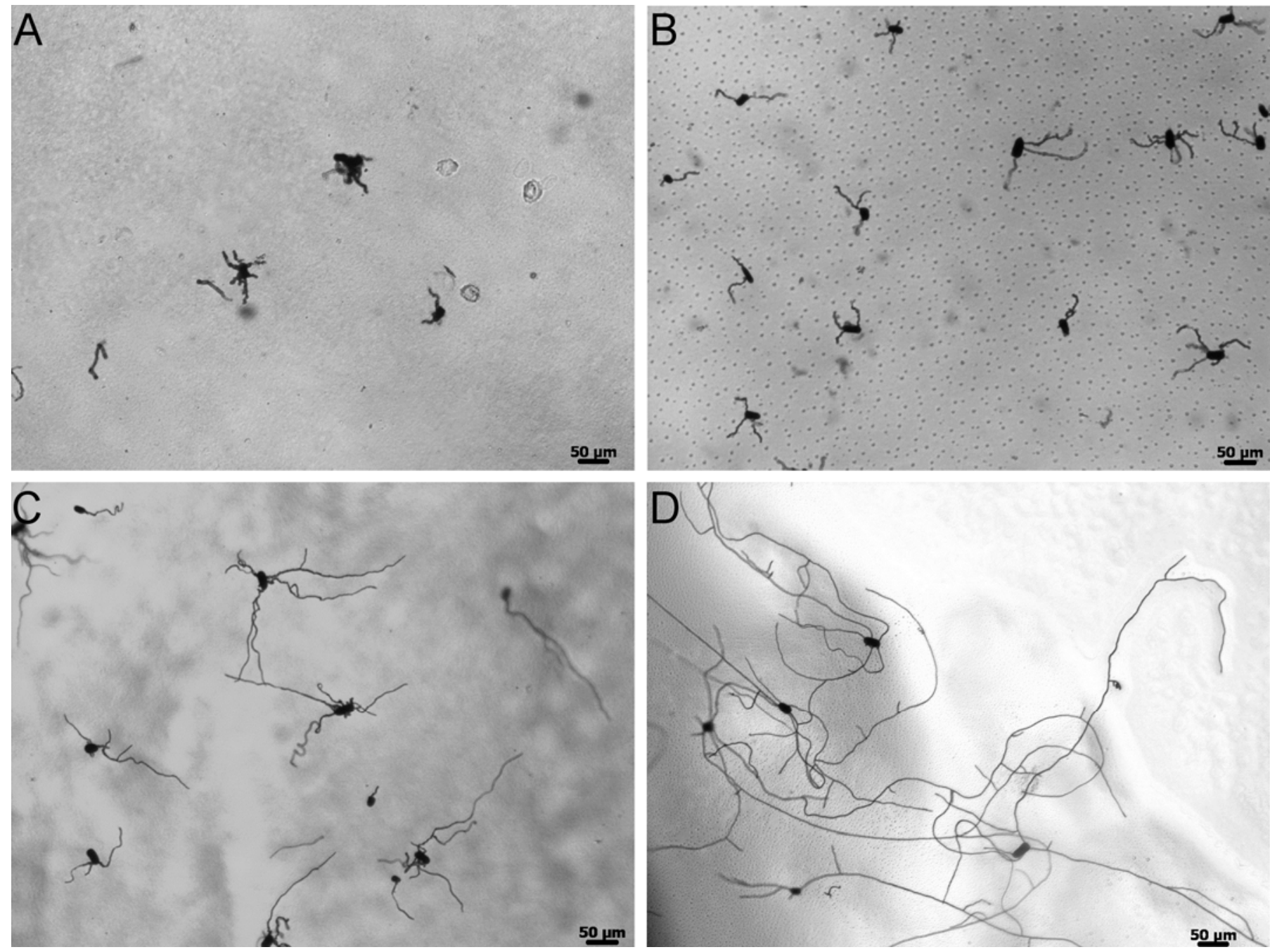

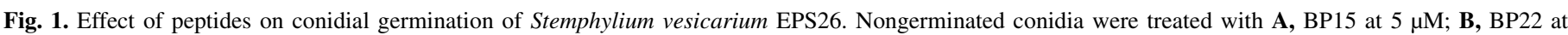
$25 \mu \mathrm{M}$; or $\mathbf{C}$, BP25 at $25 \mu \mathrm{M}$; or D, were not treated. Micrographs were taken $24 \mathrm{~h}$ after the treatment. 
vesicarium was determined by analysis of variance (ANOVA) with Proc GLM in SAS. Data regarding sporulation were previously $\log _{10}(\mathrm{~S})$ transformed because the data were not normally distributed. The effect of the experiment was not significant, and pooled data of two experiments were analyzed. To determine the effect of the strategy of peptide application (preventative or curative) on disease severity in pear leaves, the data were analyzed using the area under the disease progress curve (AUDPC) (8). ANOVA with Proc GLM was used to determine the effect of the application strategy on AUDPC in addition to the effect of peptide and dose. Comparisons of the means were performed with Fisher's protected least significant difference test at $P=0.05$. Because the effect of the experiment was significant, the data for each experiment were analyzed separately. The effect of the time of peptide application after the onset of $S$. vesicarium conidial germination on pear leaves was determined with repeatedmeasures ANOVA using Proc GLM. To determine the relationship between disease severity and peptide application time, $F$ tests were used. Mauchly's sphericity test was used to examine the covariance matrix. Differences among the various strategies were determined.

\section{RESULTS}

Effect of peptides on conidial germination. The peptides showed different effects on the germination of $S$. vesicarium conidia (Table 1). In total, 8 of 12 peptides were capable of reducing the germination at concentrations $\leq 100 \mu \mathrm{M}$. Three peptides (BP15, BP22, and BP25) were the most effective, and BP15 presented the lowest MIC $(10 \mu \mathrm{M})$ for the conidial germination of the two pathogenic strains tested. Fewer germ tubes were observed, and these germ tubes were shorter than those in the nontreated control. BP22 and BP25 also caused a significant reduction in conidial germination, with an MIC of $50 \mu \mathrm{M}$.

Microscopic observations of the conidia showed that, at doses lower than the MIC, all peptides, except BP38, were capable of reducing the length of the germ tubes an average of $75 \%$ compared with the nontreated control at $48 \mathrm{~h}$. When the peptides were applied at doses lower than their respective MICs (BP15 at $5 \mu \mathrm{M}, \mathrm{BP} 22$ at $25 \mu \mathrm{M}$, and BP25 at $25 \mu \mathrm{M}$ ), the germ tubes were shorter, more wrinkled, and thicker than those in the nontreated control (Fig. 1).

Inhibition of growth and sporulation. BP15, BP22, and BP25 significantly reduced $(P=0.001)$ fungal growth compared with the nontreated control (50 to $95 \%$ ). The highest growth reduction was achieved with BP15 at $50 \mu \mathrm{M}$ and BP22 at $100 \mu \mathrm{M}$ (Fig. 2A). Similar results were observed for sporulation, and peptides were capable of significantly reducing conidia production by 10 - to 1,000-fold (Fig. 2B). Thus, peptides BP15 and BP22 were selected for further studies.

Sporicidal activity. The sporicidal activity of BP15, BP22, and BP25 was evaluated by comparing the viability of conidia that were exposed to different doses of peptides for 6,24 , and $48 \mathrm{~h}$. The results were similar for the two experiments (data not shown). The sporicidal activity was very low for the different combinations of incubation periods and peptides used, because no differences in conidial viability were observed. BP22 and BP25 did not significantly inhibit fungal growth compared with the nontreated control regardless of the treatment and dose.

Fungal interaction with BP15-FITC. The application of the BP15-FITC conjugate to nongerminated conidia showed that the peptide did not interact with the surface of the conidia because no fluorescence was observed. When the conjugate was applied at 6 or $15 \mathrm{~h}$ after the onset of germination, the peptide was visualized in $<5 \mathrm{~min}$ as intense fluorescence on the germ tubes and hyphae (Fig. 3). After $24 \mathrm{~h}$, the morphology of hyphae changed, showing damaged, constricted regions and intense fluorescence. Fluorescence was also observed in some regions of the conidia surface, indicating that the peptide was partially adhered. However, the newly formed germ tubes were damaged and were shorter than in nontreated controls. In treatments corresponding to applications of peptide $15 \mathrm{~h}$ after germination $(10$ or $100 \mu \mathrm{M})$, the growth of germ tubes stopped, and no further elongation of hyphae was observed after $24 \mathrm{~h}$. The morphology of hyphae also changed in relation to the nontreated control (Fig. 4). Short hyphae were frequently observed (Fig. 4A) that showed morphological alterations, with constricted regions, thick cells forming the hyphae, and septa that were much closer together. In some cases, condensed mycelia aggregates around the conidia were observed that did not appear in nontreated controls (Fig. 4A).

Evaluation of preventative and curative strategies for peptide application. In general, the size of leaf lesions was dependent on the strategy and not on the dose of peptide (Table 2; Fig. 5). According to the AUDPC, in both experiments, the application strategy for the two peptides (BP15 and BP22) had a significant effect $(P<0.001)$ (Table 2; Fig. 5). The better strategy was the curative strategy, which reduced the AUDPC between 67 and $77 \%$ and between 45 and $58 \%$ in relation to the nontreated control in experiments 1 and 2, respectively. The preventative application did not inhibit the disease, and the severity and AUDPC were not significantly different from that of the nontreated controls $(P<0.001)$ (Table 2). When BP15 and BP22 were applied curatively, all doses $(50,100$, or $200 \mu \mathrm{M})$ significantly reduced the AUDPC in relation to the nontreated control $(P<0.001)$. In experiment 1 , the AUDPC for both peptides at different doses was not significantly different from

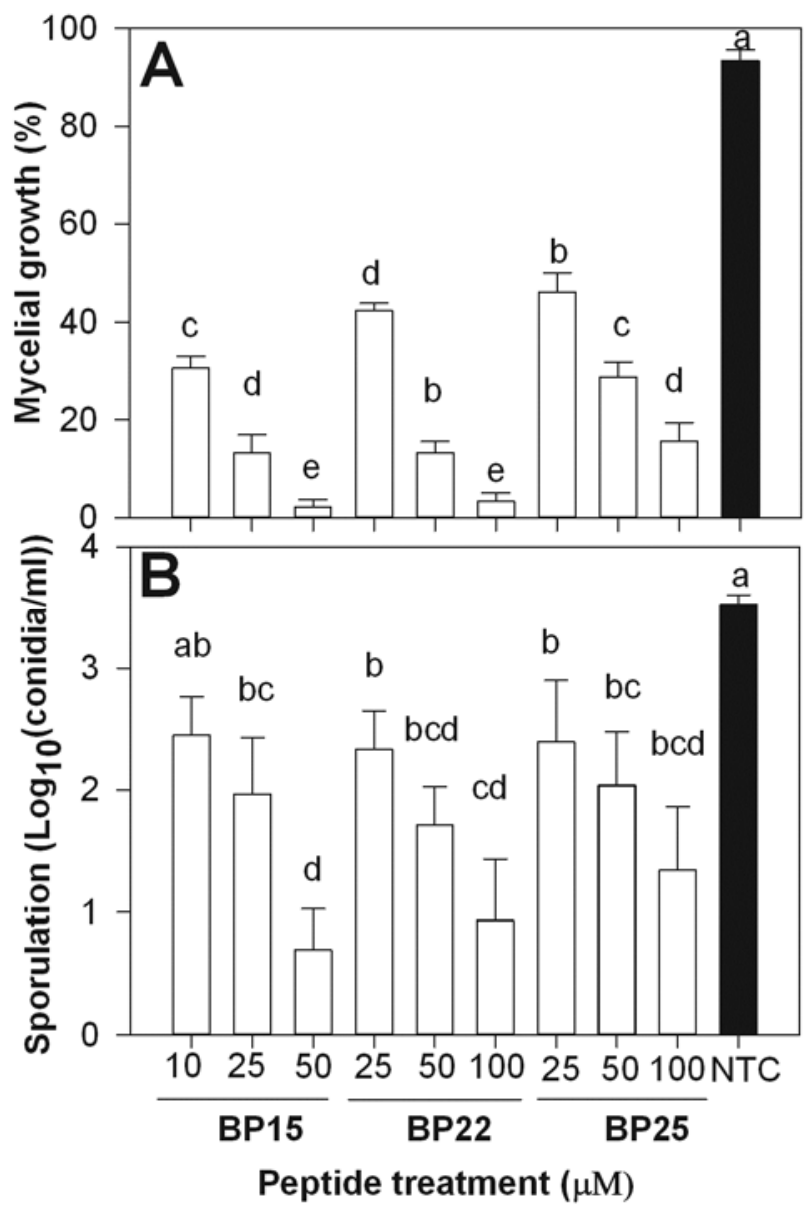

Fig. 2. Effect of different concentrations of the peptides BP15, BP22, and BP25 on A, mycelial growth and B, sporulation of Stemphylium vesicarium EPS26 compared with the nontreated control (NTC). Results are presented as the means \pm standard error of two experiments, in which each treatment was tested in triplicate. Bars marked with same letter are not significantly different according to Fisher's protected least significant test $(P<0.01)$. 
that of thiram when the peptides were applied curatively. Despite these results, some brown spot lesions were observed, indicating that none of the treatments was completely effective.

The effect of peptide application strategies was also evaluated using SEM, and some differences in the morphologies of the conidia and hyphae were observed. In the preventative treatments, the development of $S$. vesicarium was similar to that observed in the nontreated controls. The hyphae grew normally, and they were capable of entering the stomata (Fig. 6E and F). Nevertheless, when peptides were applied after the onset of germination, hyphal development was altered and fewer hyphae were formed compared with the nontreated control (Fig. 6B and C). The fungicide thiram was more effective in the control of infections, and very few hyphae appeared (Fig. 6D).

In experiments performed to determine the effect of delayed peptide application after the beginning of germination, the disease severity increased over time $(P<0.001)$ for all strategies evaluated $(6,12,15,18$, and $24 \mathrm{~h}$ after the onset of germination) (Fig. 7). Overall, the efficacy of control using BP15 was higher than that achieved using BP22 (Fig. 7). For BP15, the disease severity depended on the treatment strategy, although it was significantly lower for all strategies $(6,12,15,18$, and $24 \mathrm{~h})$ compared with the nontreated control in both experiments $(P<0.001)$ (Fig. 7). In experiment 1 , the level of control was similar at all time points tested whereas, in experiment 2 , the best strategies were applications of peptide at 12, 15, and $18 \mathrm{~h}$ after the beginning of germination (Fig. 7). The results for the two experiments using the peptide BP22 differed. In experiment 1 , the peptide had no effect because the disease severity was similar for the 15- and 18-h strategies compared with the nontreated leaves, and the severity was significantly higher for the 6-, 12-, and 24-h strategies compared with the nontreated control $(P<0.001)$ (Fig. 7). In experiment 2 , the disease severity
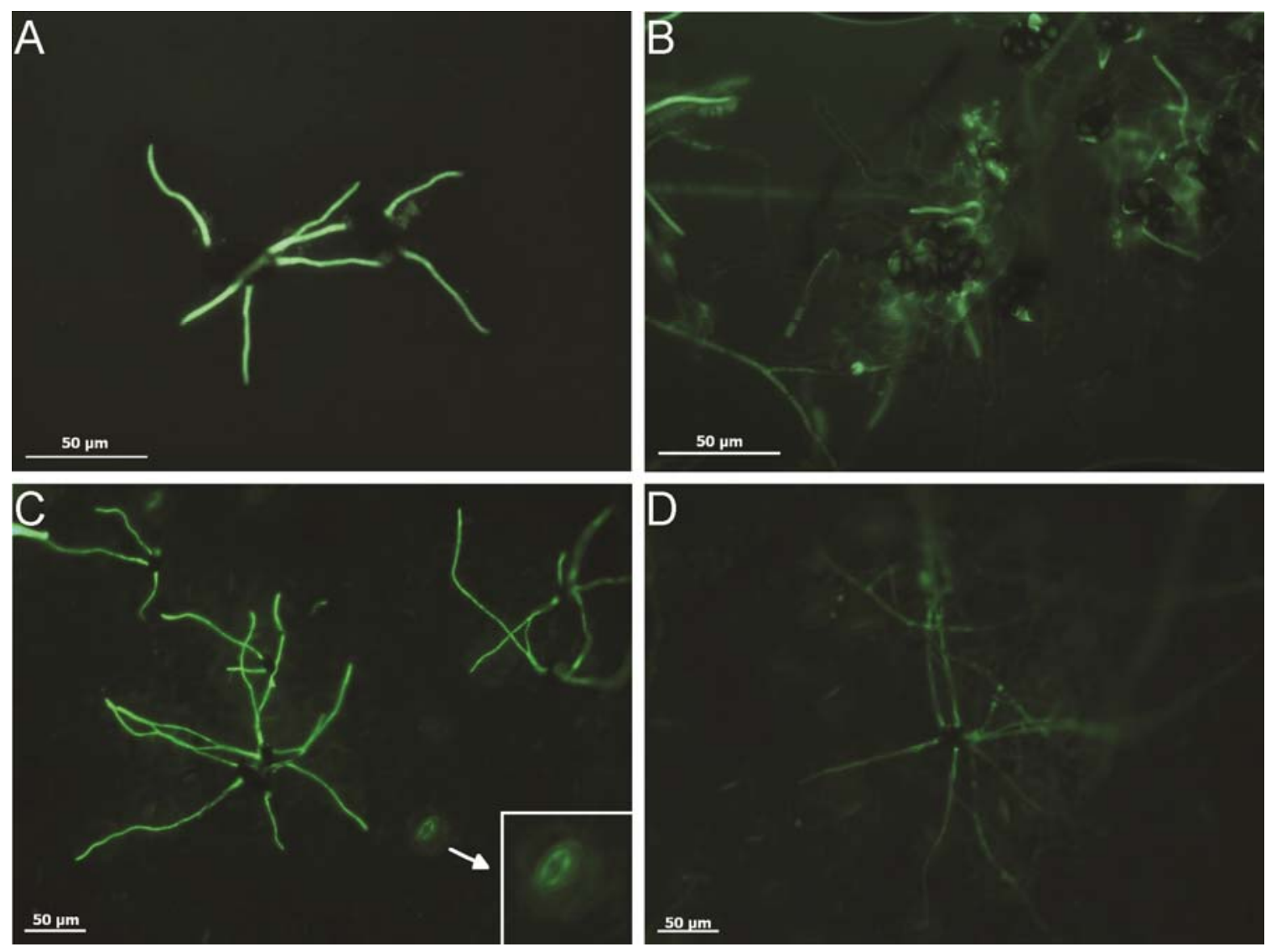

Fig. 3. Interaction of the BP15 fluorescein 5-isothiocyanate conjugate with Stemphylium vesicarium EPS26. A and B, In vitro conditions; and C and D, leaves treated curatively with peptide at $100 \mu \mathrm{M}$. Peptide treatments were applied $6 \mathrm{~h}$ after pathogen inoculation. Micrographs were taken immediately after the treatment (A and C) or $24 \mathrm{~h}$ after of incubation (B and D). In frame C, stoma is magnified.

TABLE 2. Effects of the preventative and curative application of peptides at different doses on the severity of infection caused by Stemphylium vesicarium in detached pear leaves

\begin{tabular}{|c|c|c|c|c|c|}
\hline \multirow[b]{3}{*}{ Peptide } & \multirow[b]{3}{*}{ Dose $(\mu \mathrm{M})$} & \multicolumn{4}{|c|}{$\mathrm{AUDPC}^{\mathrm{z}}$} \\
\hline & & \multicolumn{2}{|c|}{ Preventative } & \multicolumn{2}{|c|}{ Curative } \\
\hline & & Exp. 1 & Exp. 2 & Exp. 1 & Exp. 2 \\
\hline \multirow[t]{3}{*}{ BP15 } & 50 & $9,031 \mathrm{a}$ & $7,667 \mathrm{ab}$ & $2,136 \mathrm{~b}$ & $3,589 \mathrm{~b}$ \\
\hline & 100 & $8,545 \mathrm{a}$ & 7,440 abc & $1,733 \mathrm{~b}$ & $3,630 \mathrm{~b}$ \\
\hline & 200 & $7,264 \mathrm{a}$ & $5,435 \mathrm{c}$ & $1,716 \mathrm{~b}$ & $3,146 \mathrm{~b}$ \\
\hline \multirow[t]{3}{*}{ BP22 } & 50 & $8,969 \mathrm{a}$ & $8,104 \mathrm{a}$ & $1,769 \mathrm{~b}$ & $4,117 b$ \\
\hline & 100 & $9,429 \mathrm{a}$ & $6,958 \mathrm{abc}$ & $2,364 \mathrm{~b}$ & $3,119 \mathrm{~b}$ \\
\hline & 200 & $5,933 \mathrm{a}$ & $5,948 \mathrm{bc}$ & $2,397 \mathrm{~b}$ & $3,716 \mathrm{~b}$ \\
\hline Thiram & $\ldots$ & $727 \mathrm{~b}$ & $91 \mathrm{~d}$ & $287 \mathrm{~b}$ & $377 \mathrm{c}$ \\
\hline Nontreated & $\ldots$ & $8,752 \mathrm{a}$ & $6,183 a b c$ & $7,469 \mathrm{a}$ & $7,532 \mathrm{a}$ \\
\hline
\end{tabular}

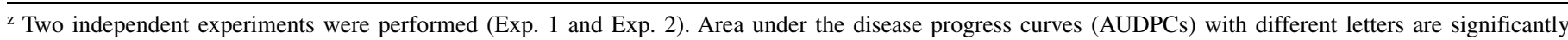
different accordingly to Fisher's protected least significant difference test at $P=0.05$. 
was significantly lower for all strategies compared with the nontreated control $(P=0.0030)$.

To investigate the interaction between BP15 and $S$. vesicarium on leaves, this assay was repeated with the BP15-FITC conjugate (Fig. 3 ). When the BP15-FITC conjugate was applied, the peptide began to interact with hyphae very quickly. In the two experiments, the peptide adhered to or entered the hyphae but did not interact with the conidia. These results were similar to those obtained in the in vitro assays. Another important observation was that the peptide was also located in the stomata.

\section{DISCUSSION}

The present work demonstrates that AMPs offer new possibilities for use as fungicides to control brown spot of pear. Several peptides from the CECMEL11 library can inhibit $S$. vesicarium under in vitro and ex vivo conditions. Previous studies have reported that the peptides BP76 and BP100 showed activity against the phytopathogenic bacteria $E$. amylovora, $X$. axonopodis pv. vesicatoria, and $P$. syringae pv. syringae and that BP15, BP21, and BP34 were effective against some fungi, such as $F$. oxysporum or Penicillium expansum $(5,6)$. In the present study, the peptides BP15, BP22, and BP25 reduced the germination of conidia with MICs in the range of 10 to $50 \mu \mathrm{M}$. These MIC values were similar to others reported previously for AMPs in different pathosystems, although the methodology and the pathogens used were different $(5,9,21,22)$. In our experiments performed under in vitro conditions, the effect of peptides on fungal development was
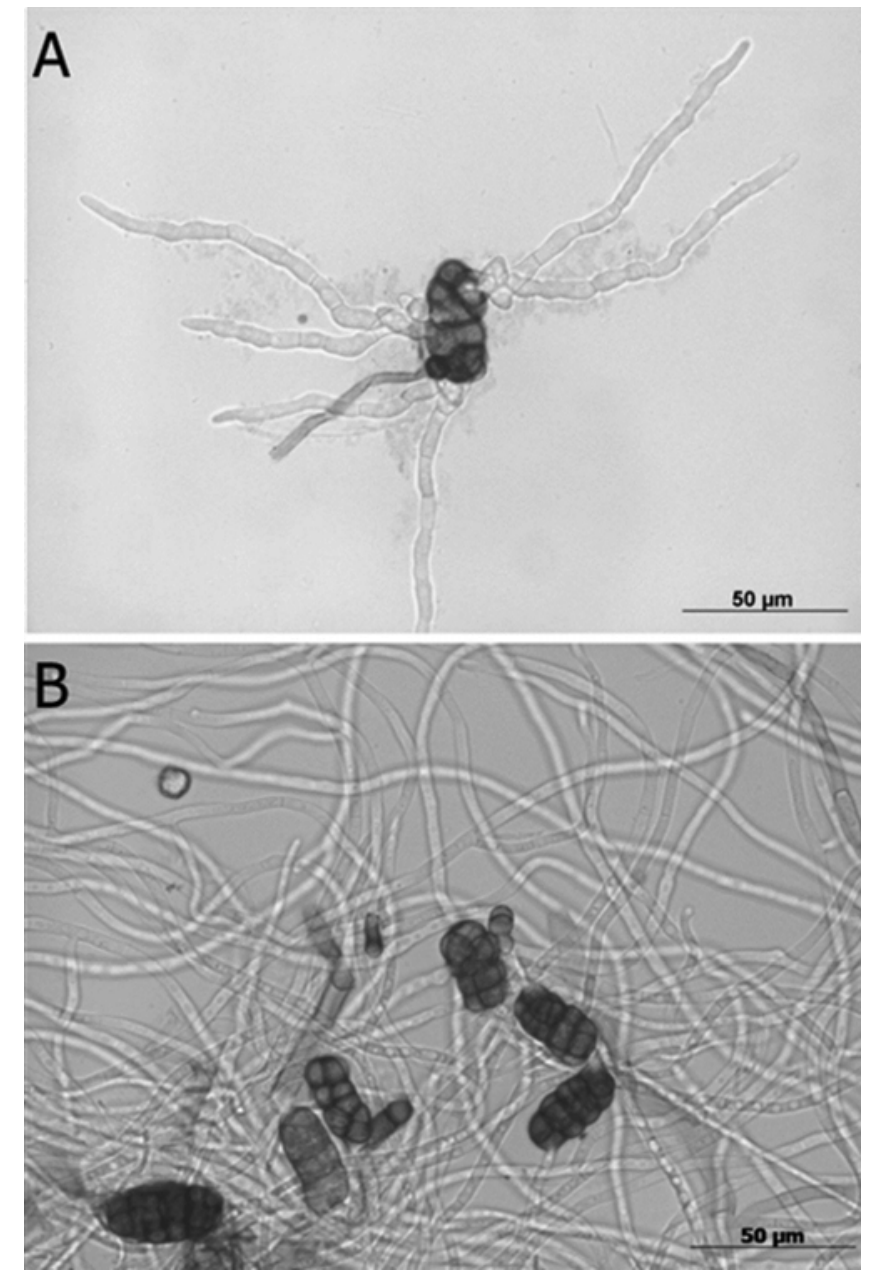

Fig. 4. Effect of the peptide BP15 on germ tubes and hyphae of Stemphylium vesicarium EPS26. Nongerminated conidia were A, treated with BP15 at $100 \mu \mathrm{M}$ or $\mathbf{B}$, not treated. Micrographs were taken $24 \mathrm{~h}$ after the treatment. evaluated by optical microscopy instead of spectrophotometric methods because the hyphae mass formation of germinated conidia, as well as their precipitation and filamentous growth, did not permit accurate photometric measurements $(25,30)$. Additionally, microscopy is more accurate and informative than optical density measures because it allows the identification of morphological changes caused by peptide treatment, especially in the case of pluricellular conidia, which have multiple germination tubes emerging from the spore, as is the case for S. vesicarium. This methodology was used by other authors to examine changes in fungal mass (1). Thus, morphological changes in germ tubes were observed when conidia of $S$. vesicarium were treated with effective peptides. Similar results have been reported in Phytophthora infestans, A. solani, A. alternata, B. cinerea, Penicillium digitatum, and $F$. oxysporum using pep6, pep7, pep11, C14KLLK, PAF26, or $C c$-GRP $(4,22,26,27,32)$. Additionally, it was observed that BP15 and BP22 could reduce the development of germ tubes and hyphae as well as the sporulation of $S$. vesicarium. It is important to note that no sporicidal effects were observed, contrary to what was reported in a similar study with CECMEL11 peptides, which showed a sporicidal effect against $F$. oxysporum and $P$. expansum at low concentrations $(<5.0 \mu \mathrm{M})$ (5), and a study showing the sporicidal effects of PAF26 against P. digitatum at $30 \mu \mathrm{M}(27)$.

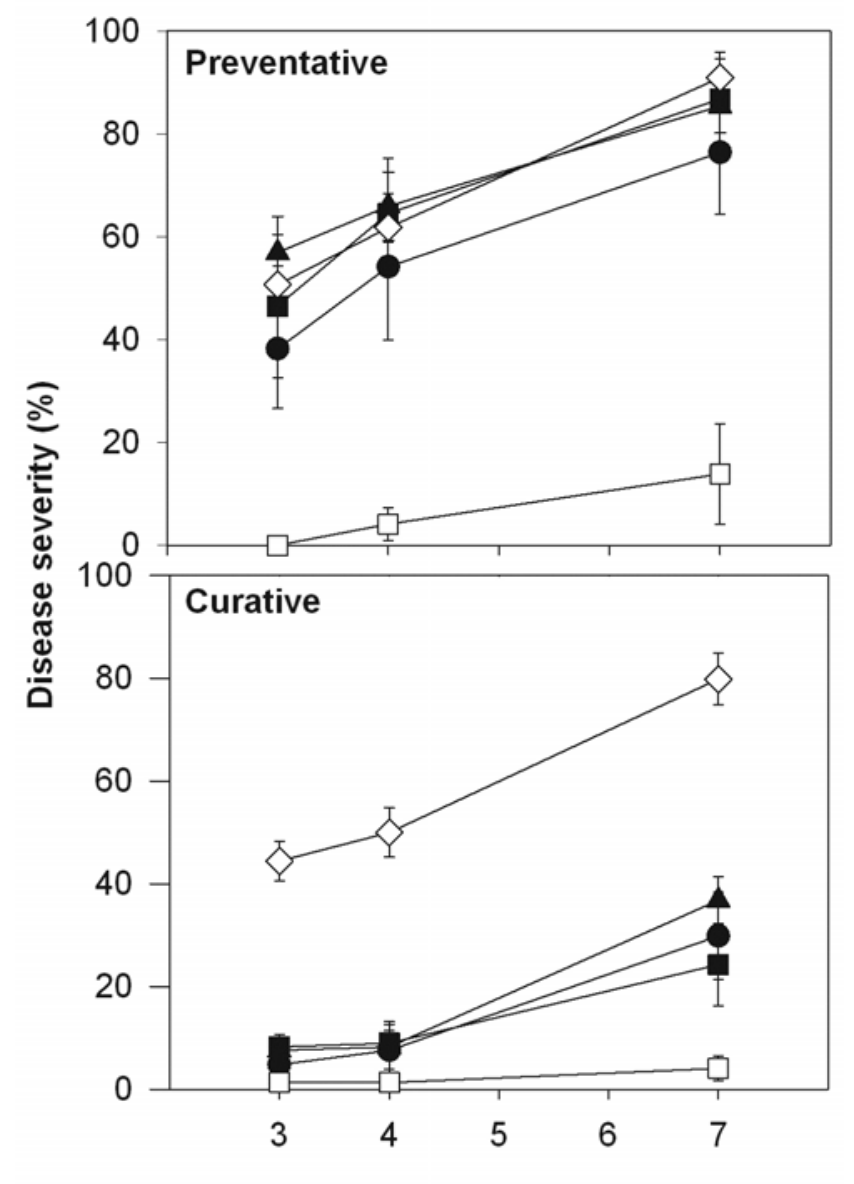

Days post inoculation (dpi)

Fig. 5. Disease severity progress on detached leaves treated preventatively or curatively with the peptide BP15 at $50(\boldsymbol{\Delta}), 100(\boldsymbol{\square})$, and $200(\boldsymbol{\bullet}) \mu \mathrm{M}$; the fungicide thiram $(\square)$; or not treated $(\diamond)$. In the preventative strategy, leaves were first treated with peptide or thiram, and after $3 \mathrm{~h}$, they were inoculated with Stemphylium vesicarium EPS26 ( $10^{3}$ conidia/ml). In the curative strategy, the pathogen was inoculated and, after overnight incubation, the leaves were treated with the peptide or with thiram. Bars represent the standard error of the means. Data correspond to experiment 1. Similar results were obtained in experiment 2 . 

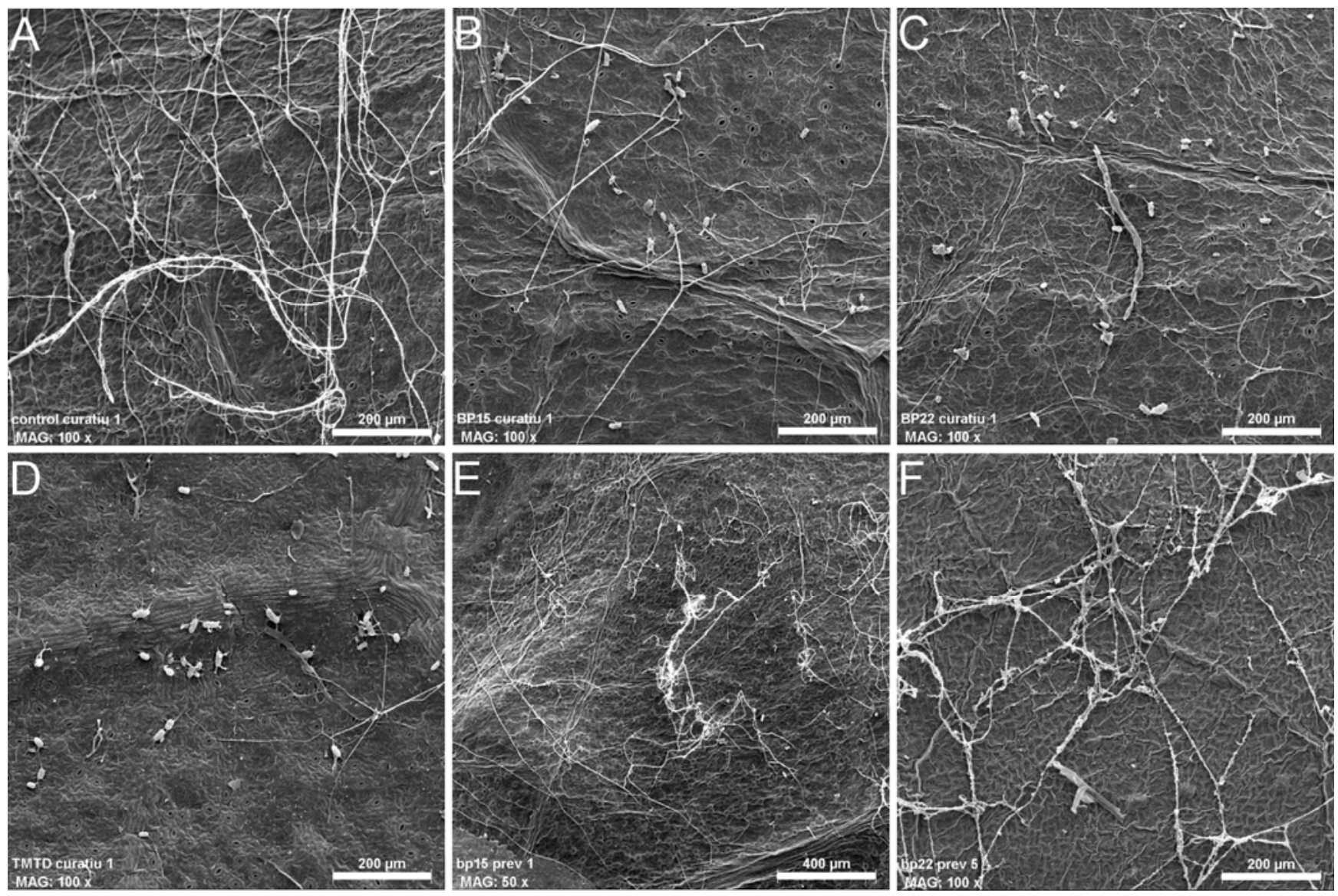

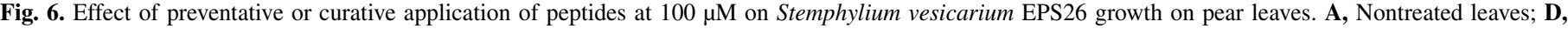

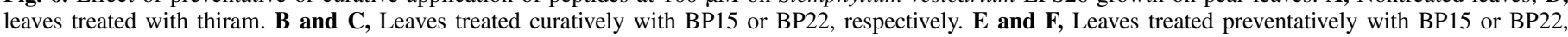
respectively. Scanning electron micrographs were taken 10 days after the peptide applications.

When the interaction between BP15 and nongerminated or germinated conidia of $S$. vesicarium was studied using the BP15FITC conjugate, the peptide was found to be located in germ tubes and hyphae a few minutes after application, where it remained for at least $24 \mathrm{~h}$. However, the peptide did not bind to nongerminated conidia. The application of the peptide to hyphae caused malformations and irreversibly blocked their development. This suggests that the targets of BP15 are hyphae and germ tubes; this has also been described in other antifungal studies (Aspergillus spp., Fusarium spp., and P. digitatum) with Cecropin A and PAF26 $(11,27)$. On the other hand, the newly formed germ tubes exhibited malformations, and they did not develop properly. Further studies are needed to fully understand the mechanism of action of the BP15 and BP22 peptides.

The efficacy of BP15 and BP22 peptides in the leaf infection assays differed depending on the application strategy (i.e., application before or after pathogen inoculation). When applied preventatively ( $3 \mathrm{~h}$ before inoculation), the efficacy was lower compared with curative application ( $15 \mathrm{~h}$ after inoculation) at all tested doses $(50,100$, and $200 \mu \mathrm{M})$. The low efficacy of preventative applications could be explained by the inactivation or binding of the peptides to the leaf surface. It should be noted that BP15-FITC was also found to adhere to the stomata. The fact that the BP15-FITC conjugate bound to the stomata, likely adhering to polysaccharides of guard cells, may indicate that BP15 forms an antimicrobial barrier to prevent $S$. vesicarium penetration into the leaf through the stomata. However, this possibility requires further studies. In previous reports, inactivation by proteases present on the leaf surface or other factors such as phenolic compounds have been implicated in the loss of peptide activity (1). The inhibition of some peptides, such as BP100 and BP143, by leaf extracts has been described (14). The degradation was reported to be very rapid because, in $<3 \mathrm{~h}$, the peptides were unable to affect the germination of the conidia. Previous studies have demonstrated that some peptides are degraded from 40 to $60 \%$ in $<1 \mathrm{~h}(14,29)$. Thus, protease digestion stability is a desired property in AMPs to ensure that the molecules have a reasonable half-life in the plant environment. Most likely, modifying BP15 and BP22 to increase their stability to proteases would increase their efficacy in controlling infections when applied preventatively, as has been described for BP100 and D-amino acid derivatives (14). However, the low efficacies of preventative treatments can also be explained by the absence of sporicidal activity.

One of the most important observations of the present study was that the peptide BP15 rapidly reduced pear leaf infections when applied curatively at all doses studied. Even when spots appeared on the surfaces of treated leaves, their diameters were smaller compared with those observed in the nontreated control. This result may be explained by the fact that $S$. vesicarium releases a specific phytotoxin during conidial germination and, when the peptide blocks the fungal development process, certain amounts of the toxin have already been delivered to leaf tissues (18). The efficacy of curative applications is also interesting because, at the moment, few fungicides with postinfection activity are available for use on pear (18). In addition, in the majority of reports, the efficacy of AMPs against bacteria or fungi was tested preventatively or with mixtures of peptide and pathogen before inoculation $(4,22,26)$. However, these methodologies do not simulate natural conditions in the field.

The interaction of the peptide BP15 with fungal structures revealed that the peptide binds directly to the hyphae, thus confirming the results obtained in vitro. At $24 \mathrm{~h}$ after treatment, the 


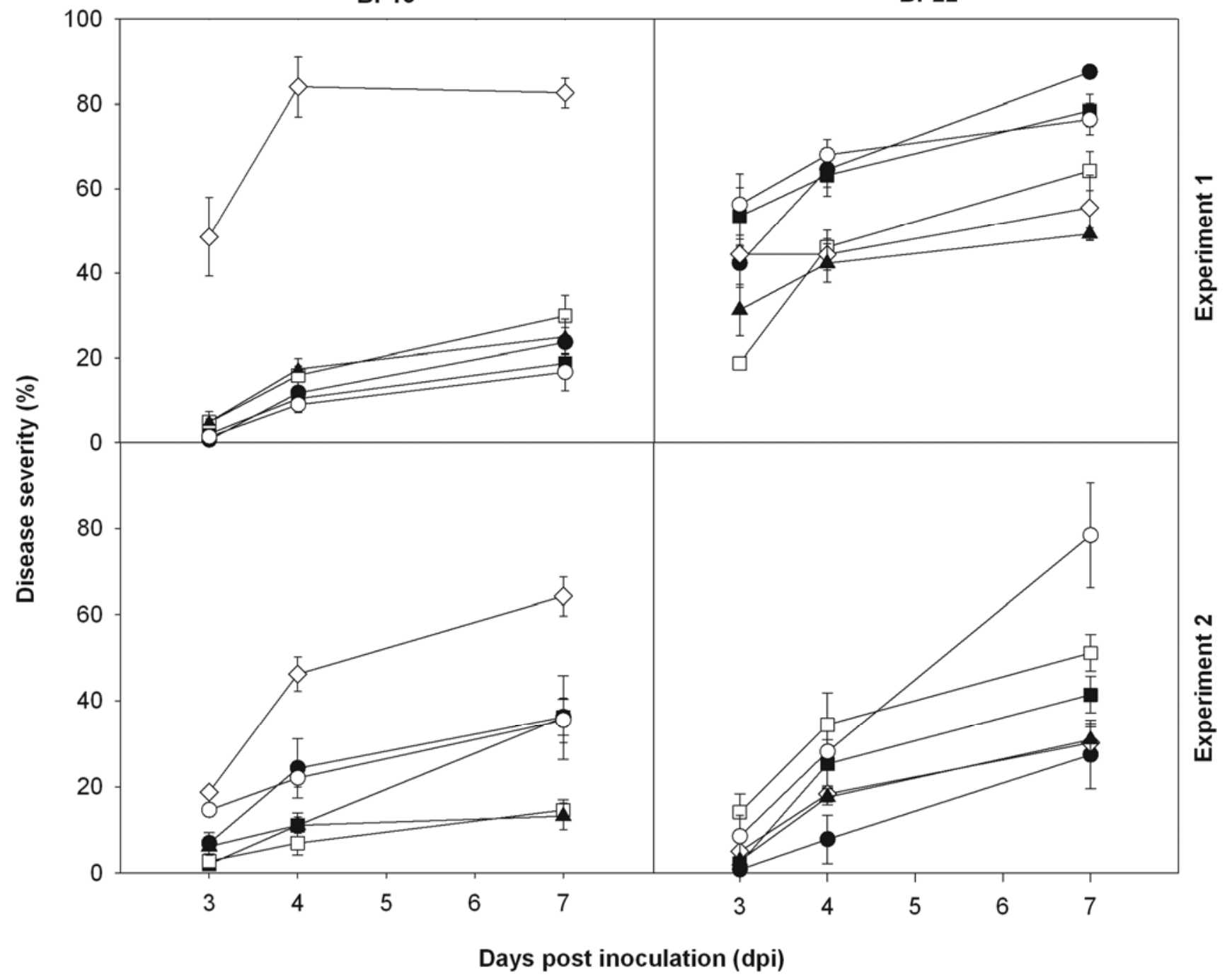

Fig. 7. Disease severity on leaves treated according to the curative strategy with BP15 or BP22 at $100 \mu \mathrm{M}$ in the two experiments. Treatments were performed $6(\bullet), 12(\square), 15(\square), 18(\Delta)$, and $24(\bigcirc)$ h after pathogen inoculation. The nontreated control is also shown $(\diamond)$. Bars represent the means \pm standard error.

peptide remained adhered to the hyphae and some germinated conidia. Curative treatments with BP15 and BP22 reduced the surface area of the leaf that was occupied by hyphae, and more detailed studies were performed to determine the dynamics of control infections. Applications of BP15 at all the times tested (6, $12,15,18$, and $24 \mathrm{~h}$ postinoculation) revealed its high efficacy for infection control, which was higher than that achieved with BP22. Consistently, the disease severity was lower on leaves that received applications of BP15 compared with untreated controls and similar to that observed using the fungicide thiram. The application of thiram and other fungicides is scheduled in commercial orchards with the aid of a brown spot of pear forecast system, BSPcast, which determines the level of daily infection risk (19). However, these fungicides have few or no curative effects on brown spot infections. The capacity of BP15 to control an infection process that has already started could permit its use in combination with the BSPcast in a more efficient manner.

We conclude that BP15 could be used as a possible complement of classical synthetic fungicides to control brown spot of pear in pear orchards. Currently, we are evaluating its efficacy in controlling brown spot of pear under natural conditions. However, to incorporate this AMP into an integrated management program, it will be necessary to evaluate not only its efficacy but also its impact on the ecosystem, especially its effect on epiphytic microbiota on leaves and fruit. Another issue is the cost, which would be very high for field application. However, efforts are being made to decrease the cost of production, including the use of plant or microbial biofactories $(7,10)$.

\section{ACKNOWLEDGMENTS}

This research was supported, in part, by grants from the Ministerio de Educación y Ciencia (AGL2009-09829/AGR) of Spain and the Comissió Interdepartamental de Recerca i Tecnologia of the Generalitat de Catalunya (2009SGR00812). M. Puig was the recipient of a predoctoral fellowship from Universitat de Girona (BR10-17). We thank the Microscopy Unit of the Technical Research Services of the University of Girona for helpful collaboration and technical assistance.

\section{LITERATURE CITED}

1. Alan, A. R., and Earle, E. D. 2002. Sensitivity of bacterial and fungal plant pathogens to the lytic peptides, MSI-99, magainin II, and cecropin B. Mol. Plant-Microbe Interact. 15:701-708.

2. Alberoni, G., Cavallini, D., Collina, M., and Brunelli, A. 2010. Characterisation of the first Stemphylium vesicarium isolates resistant to strobilurins in Italian pear orchards. Eur. J. Plant Pathol. 126:453-457.

3. Alberoni, G., Collina, M., Pancaldi, D., and Brunelli, A. 2005. Resistance to dicarboximide fungicides in Stemphylium vesicarium of Italian pear orchards. Eur. J. Plant Pathol. 113:211-219.

4. Ali, G. S., and Reddy, A. S. N. 2000. Inhibition of fungal and bacterial plant pathogens by synthetic peptides: In vitro growth inhibition, 
interaction between peptides and inhibition of disease progression. Mol. Plant-Microbe Interact. 13:847-859.

5. Badosa, E., Ferre, R., Francés, J., Bardají, E., and Feliu, L. 2009. Sporicidal activity of synthetic antifungal undecapeptides and control of Penicillium rot of apples. Appl. Environ. Microbiol. 75:5563-5569.

6. Badosa, E., Ferre, R., Planas, M., Feliu, L., Besalú, E., Cabrefiga, J., Bardají, E., and Montesinos, E. 2007. A library of linear undecapeptides with bactericidal activity against phytopathogenic bacteria. Peptides 28:2276-2285.

7. Badosa, E., Moiset, G., Montesinos, L., Talleda, M., Bardají, E., Feliu, L., Planas, M., and Montesinos, E. 2013. Derivatives of the antimicrobial peptide BP100 for expression in plant systems. PLoS One 8:e85515.

8. Campbell, C., and Madden, L. 1990. Introduction to Plant Disease Epidemiology, 1st ed. John Wiley \& Sons, New York.

9. Cavallarin, L., Andreu, D., and San Segundo, B. 1998. Cecropin Aderived peptides are potent inhibitors of fungal plant pathogens. Mol. Plant-Microbe Interact. 11:218-227.

10. Company, N., Nadal, A., La Paz, J.-L., Martínez, S., Rasche, S., Schillberg, S., Montesinos, E., and Pla, M. 2013. The production of recombinant cationic $\alpha$-helical antimicrobial peptides in plant cells induces the formation of protein bodies derived from the endoplasmic reticulum. Plant Biotechnol. J. 12:81-92. Online publication. doi:10.1111/pbi.12119

11. DeLucca, A. J., Bland, J. M., Jacks, T. J., Grimm, C., Cleveland, T. E., and Walsh, T. J. 1997. Fungicidal activity of cecropin A. Antimicrob. Agents Chemother. 41:481-483.

12. DeLucca, A., and Walsh, T. 1999. Antifungal peptides: Novel therapeutic compounds against emerging pathogens. Antimicrob. Agents Chemother. 43:1-11.

13. Ferre, R., Badosa, E., Feliu, L., Planas, M., and Montesinos, E. 2006. Inhibition of plant-pathogenic bacteria by short synthetic cecropin amelittin hybrid peptides. Appl. Environ. Microbiol. 72:3302-3308.

14. Güell, I., Cabrefiga, J., Badosa, E., Ferre, R., Talleda, M., Bardají, E., Planas, M., Feliu, L., and Montesinos, E. 2011. Improvement of the efficacy of linear undecapeptides against plant-pathogenic bacteria by incorporation of D-amino acids. Appl. Environ. Microbiol. 77:26672675.

15. Hancock, R. E. W., and Lehrer, R. 1998. Cationic peptides: A new source of antibiotics. Trends Biotechnol. 16:82-88.

16. Hancock, R. E. W., and Sahl, H.-G. 2006. Antimicrobial and host-defense peptides as new anti-infective therapeutic strategies. Nat. Biotechnol. 24:1551-1577.

17. Keymanesh, K., Soltani, S., and Sardari, S. 2009. Application of antimicrobial peptides in agriculture and food industry. World J. Microbiol. Biotechnol. 25:933-944.

18. Llorente, I., and Montesinos, E. 2006. Brown Spot of Pear: An emerging disease of economic importance in Europe. Plant Dis. 90:1368-1375.
19. Llorente, I., Vilardell, P., Bugiani, R., Gherardi, I., and Montesinos, E. 2000. Evaluation of BSPcast disease warning system in reduced fungicide use programs for management of brown spot of pear. Plant Dis. 84:631637.

20. Llorente, I., Vilardell, A., Vilardell, P., Pattori, E., Bugiani, R., Rossi, V., and Montesinos, E. 2010. Control of brown spot of pear by reducing the overwintering inoculum through sanitation. Eur. J. Plant Pathol. 128:127141.

21. López-García, B., González-Candelas, L., Pérez-Payá, E., and Marcos, J. F. 2000. Identification and characterization of a hexapeptide with activity against phytopathogenic fungi that cause postharvest decay in fruits. Mol. Plant-Microbe Interact. 13:837-846.

22. Makovitzki, A., Viterbo, A., Brotman, Y., Chet, I., and Shai, Y. 2007. Inhibition of fungal and bacterial plant pathogens in vitro and in planta with ultrashort cationic lipopeptides. Appl. Environ. Microbiol. 73:66296636.

23. Montesinos, E. 2007. Antimicrobial peptides and plant disease control. FEMS Microbiol. Lett. 270:1-11.

24. Montesinos, E., Badosa, E., Cabrefiga, J., Planas, M., Feliu, L., and Bardají, E. 2012. Antimicrobial peptides for plant disease control. From discovery to application. Pages 235-261 in: Small Wonders: Peptides for Disease Control. American Chemical Society, Washington, DC.

25. Montesinos, E., and Bardají, E. 2008. Synthetic antimicrobial peptides as agricultural pesticides for plant-disease control. Chem. Biodivers. 5:12251237

26. Moreno, A. B., del Pozo, A. M., Borja, M., and San Segundo, B. 2003. Activity of the antifungal protein from Aspergillus giganteus against Botrytis cinerea. Phytopathology 93:1344-1353.

27. Muñoz, A., López-García, B., and Marcos, J. F. 2006. Studies on the mode of action of the antifungal hexapeptide PAF26. Antimicrob. Agents Chemother. 50:3847-3855.

28. Muñoz, A., and Marcos, J. F. 2006. Activity and mode of action against fungal phytopathogens of bovine lactoferricin-derived peptides. J. Appl. Microbiol. 101:1199-1207.

29. Oard, S., Rush, M. C., and Oard, J. H. 2004. Characterization of antimicrobial peptides against a US strain of the rice pathogen Rhizoctonia solani. J. Appl. Microbiol. 97:169-180.

30. Pryor, S., Gibson, D., Bergstrom, G., and Walker, L. 2007. Minimization of between-well sample variance of antifungal activity using a highthroughput screening microplate bioassay. Biotechniques 42:168-172.

31. Zasloff, M. 2002. Antimicrobial peptides of multicellular organisms. Nature 415:389-395.

32. Zottich, U., Da Cunha, M., Carvalho, A. O., Dias, G. B., Casarin, N., Vasconcelos, I. M., and Gomes, V. M. 2013. An antifungal peptide from Coffea canephora seeds with sequence homology to glycine-rich proteins exerts membrane permeabilization and nuclear localization in fungi. Biochim. Biophys. Acta 1830:3509-3516. 